
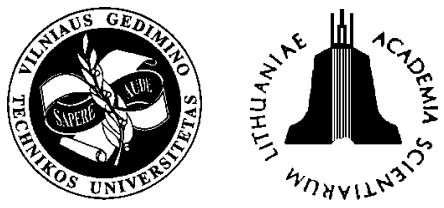

ISSN 1648-4142 TRANSPORT

\title{
ENGINEERING SOLUTIONS OF TRAFFIC SAFETY PROBLEMS OF ROAD TRANSPORT
}

\author{
Marijonas Bogdevičius $^{1}$, Olegas Prentkovskis ${ }^{2}$, Oleg Vladimirov ${ }^{3}$ \\ Dept of Transport Technological Equipment, Faculty of Transport Engineering, \\ Vilnius Gediminas Technical University, \\ Plytinès g. 27, LT-10105 Vilnius-16, Lithuania, Tel. +370 527447 83, fax +370 52745060
}

Received 2003-12-01; accepted 2004-01-15

\begin{abstract}
The authors of this paper focus on the simulation of the motor vehicle movement (taking into consideration motor vehicle dynamics, motor vehicle hydraulic brake system influence on motor vehicle movement, interaction between its wheels with road pavements, road guardrail characteristics, interaction between motor vehicle and road guardrail) on a certain road section and propose their specific solution of this problem. The presented results, illustrating the motor vehicle movement trajectories (motor vehicle braking and interaction between motor vehicle and road guardrail at various initial conditions and at various certain pavement surface of the road section under investigation) and work of a motor vehicle hydraulic brake system. Taking into consideration the presented general mathematical model and computer aided test results it is possible to investigate various road transport traffic situations as well as to investigate various transport traffic safety problems.
\end{abstract}

Keywords: motor vehicle, hydraulic brake system, wheel, dynamics, road pavement surface, road guardrail, interaction, mathematical simulation, computer aided test.

\section{Introduction}

All factors influencing accidents are divided into three groups: people (drivers, cyclists, carters, pedestrians, passengers); vehicles (cars, buses, trolleybuses, motorcycles, scooters, mopeds, bicycles); roads and streets.

It is considered that $2 / 3$ of all road accidents occur through the fault of people and only $1 / 3$ because of factors, which do not depend on the will and actions of people [1].

Accidents occur every 15 seconds, in which people suffer. One person is injured every 1.5 minute, i.e. one thousand people are injured in 24 hours. Thus, ca one million inhabitants of the earth are lost in the period of three years. The number of old vehicles, exceeding its own resources several times, has increased in Lithuania. Following statistics, one person is killed every 8 hours, and one person is injured each hour on Lithuanian roads $[1,2]$.

Each year, 4,000 - 6,000 registered road accidents occur in Lithuania (Fig 1). The most typical are as fol- lows: running over pedestrians, collision, overturning, hitting an obstacle, running over cyclists, hitting a parked vehicle and other accidents [1].

Traffic safety is becoming not only a moral, social, economical, but also a political problem in Lithuania. This problem has to be solved as quickly as possible, because Lithuania is considered to be a country of greater risk, which is very important, when integrating road transport into the European transport system.

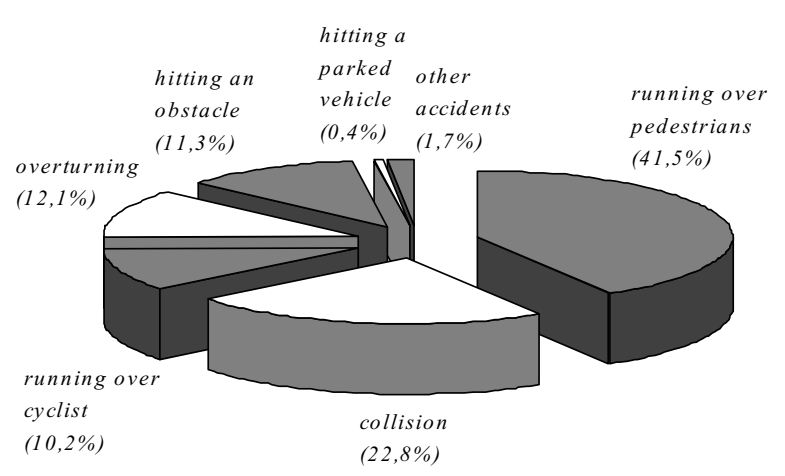

Fig 1. Statistical data of registered accidents in Lithuania (2000)

\footnotetext{
${ }^{1}$ E-mail: marius@ti.vtu.lt

${ }^{2}$ E-mail: olegas@ti.vtu.lt

${ }^{3}$ E-mail: olegvl@ti.vtu.lt
} 
Movement of the vehicle on the road is a very complicated process which depends not only on the dynamic properties of the vehicle, but also on the conditions of the road section under investigation.

The dynamics of vehicles (or individual elements of vehicle), the interaction between the vehicles and various obstacles as well as road pavement surface are investigated by Lithuanian and foreign scientists [1-22].

The authors of this paper focus on the simulation of the motor vehicle movement (taking into consideration motor vehicle dynamics, motor vehicle hydraulic brake system influence on motor vehicle movement, road guardrail characteristics, interaction between motor vehicle wheels with road pavements, interaction between motor vehicle and road guardrails) on a certain road and propose their specific solution of this problem [1, 3-9, $11,12]$.

Taking into consideration the presented general mathematical model and computer aided test results it is possible to investigate various road transport traffic situations as well as to investigate various transport traffic safety problems, for example what type and where road guardrail shall be mounted, what curvature ray of the road shall be selected so that the motor vehicle would not drive off the road carriageway, which driver caused an accident etc.

\section{Mathematical Model of the Motor Vehicle}

The motor vehicle is simulated by concentrated masses interconnected by elastic and dissipative links (Kelvin-Foight elements). The motor vehicle model consists of seven concentrated masses: body, front and rear axles and four wheels (Fig 2) [1, 3-5, 6, 8].

To describe the movement of the motor vehicle, the following generalized coordinates are introduced:

$$
\begin{aligned}
& \left\{q_{m v}\right\}^{T}=\left[\begin{array}{llllll}
x_{C} & y_{C} & z_{C} & \varphi_{x_{C}} & \varphi_{y_{C}} & \varphi_{z_{C}}
\end{array}\right. \\
& \left.z_{1} \quad \varphi_{1} \quad z_{2} \quad \varphi_{2} \quad z_{w 1} \quad z_{w 2} \quad z_{w 3} \quad z_{w 4}\right] .
\end{aligned}
$$

Movement of the motor vehicle, as movement of an intricate mechanical system, is described by the second degree LaGrange equations $[1,3-5,6,8]$.

Having inserted the expressions of the motor vehicle kinetic and potential energies, dissipative functions and the vector of generalized forces, influencing the motor vehicle, into the second degree LaGrange equations, the system of the motor vehicle movement equation is obtained, which can be written in the matrix form:

$$
\left[M_{m v}\right]\left\{\ddot{q}_{m v}\right\}=\left\{Q_{m v}\right\} ;
$$

where: $\left[M_{m v}\right]$ - matrix of motor vehicle masses; $\left\{\ddot{q}_{m v}\right\}-$ vector of generalized accelerations; $\left\{Q_{m v}\right\}$ - loading vector of the motor vehicle.
The system of equations (2) is solved by the method of Runge-Kutta [23]. For this purpose, it has to be rearranged from differential equations of the second order to differential equations of the first order:

$$
\left\{\begin{array}{l}
\frac{d}{d t}\left\{q_{m v}\right\}=\left\{\dot{q}_{m v}\right\}, \\
\frac{d}{d t}\left\{\dot{q}_{m v}\right\}=\left[M_{m v}\right]^{-1}\left\{Q_{m v}\right\} .
\end{array}\right.
$$
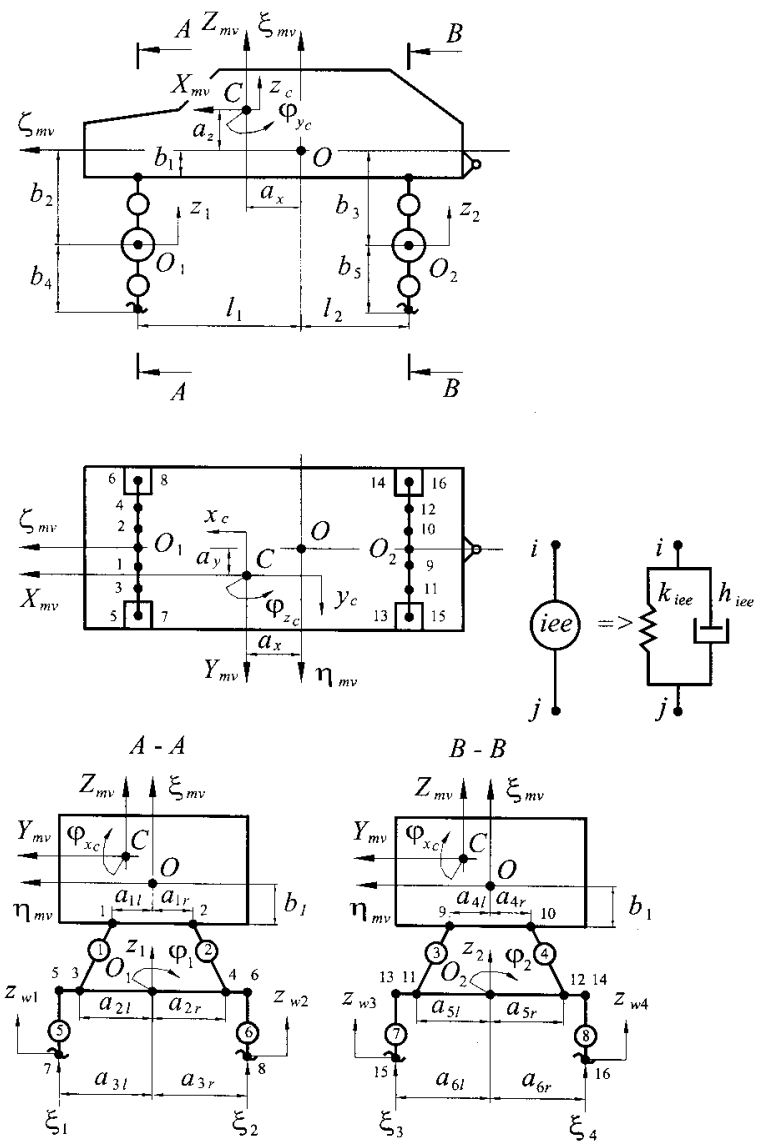

Fig 2. Motor vehicle model

\section{Mathematical Model of the Road Pavement Sur- face and Model of the Motor Vehicle Wheels and Road Pavement Surface Interaction}

To describe the road pavement surface roughness and cohesion coefficients of the road pavement and motor vehicle wheels on each nodal point of the road pavement surface, the method of finite elements is applied [1, 24].

The total pavement surface of the road section is divided into triangular finite elements (Fig 3). Certain height of the road pavement surface roughness and cohesion coefficients of road pavement surface and motor vehicle wheels in the longitudinal and transverse direc- 
tions of the motor vehicle wheels are selected in each nodal point of a finite element [1, 3-5, 6, 8].

When solving the system of equations (3), the contact between the motor vehicle wheel and road pavement surface has to be evaluated in every time step $[1,3]$.

The following conditions of contact between the motor vehicle wheel and road pavement surface are selected (Fig 4):

$$
\begin{aligned}
& z_{w j}= \begin{cases}z_{w j}, & \text { when } z_{w j} \geq \xi_{j} \\
\xi_{j}, & \text { when } z_{w j}<\xi_{j}\end{cases} \\
& \dot{z}_{w j}=\left\{\begin{array}{c}
\dot{z}_{w j}, \text { when } z_{w j} \geq \xi_{j} \text { and } \dot{z}_{w j} \geq 0 \\
0, \quad \text { when } z_{w j}<\xi_{j} \text { and } \dot{z}_{w j}<0
\end{array}\right. \\
& \ddot{z}_{w j}=\left\{\begin{array}{cl}
F_{e q j+10}, & \text { when } z_{w j} \geq \xi_{j} \text { and } F_{e q j+10} \geq 0 ; \\
0, & \text { when } z_{w j}<\xi_{j} \text { and } F_{e q j+10}<0 ;(4)
\end{array}\right.
\end{aligned}
$$

where: $z_{w j}, \dot{z}_{w j}, \ddot{z}_{w j}$-displacement, velocity and ac-

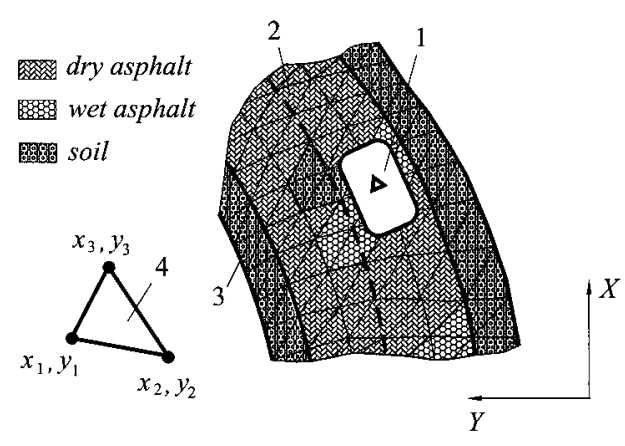

Fig 3. Expansion of the pavement surface of the road section into finite elements: 1 - motor vehicle; 2 - road carriageway; 3 - shoulder; 4 - triangular finite element

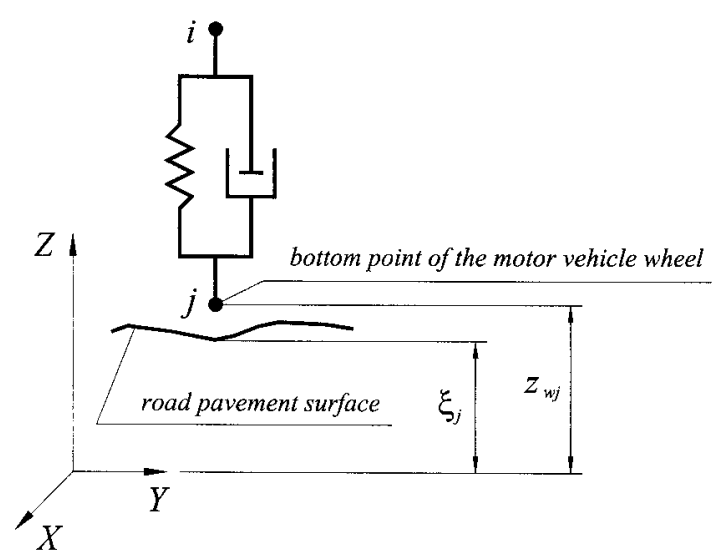

Fig 4. Identification circuit of the contact between motor vehicle wheel and road pavement surface celeration of bottom point of the motor vehicle wheel; $\xi_{j}$ - heights of road pavement surface roughness under

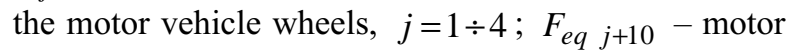
vehicle movement equations right side obtained with respect to $\dot{z}_{w j}$.

When global coordinates of the motor vehicle wheels are known, the dependence of a certain wheel on the exact finite element of the road pavement surface and the height of roughness of the road pavement surface under it can be determined $[1,3]$.

\section{Mathematical Model of the Motor Vehicle Hydrau- lic Brake System}

In this paper a motor vehicle hydraulic break system consisting of two contours is considered. The main components of the system are shown in Fig 5.

When the driver presses the brake pedal, it pushes down the piston in the master cylinder 1 , so creating pressure in the fluid in pipeline 2 . The ideal variant is when the fluid is incompressible, but in a real model it is not so. The fluid comes to the hydraulic amplifier 3, where the pressure grows up propotionally to the crossections of pistons. Two contour separator 4 is intended to prevent failure of all system, when one of the cylinders or pipelines does not work properly. When one countour lost its functions, the other continues to brake. This requirement is essential for all brake systems. During braking the pressure of fluid is transmitted to the wheel cylinders 5-8, which forces the brake pads against the revolving disc. The amplifier 3 and the difference in crossection of the cylinders allow to use a relatively small force applied on the pedal to get a large force on the brake pads.

Let's consider the system from the main cylinder.

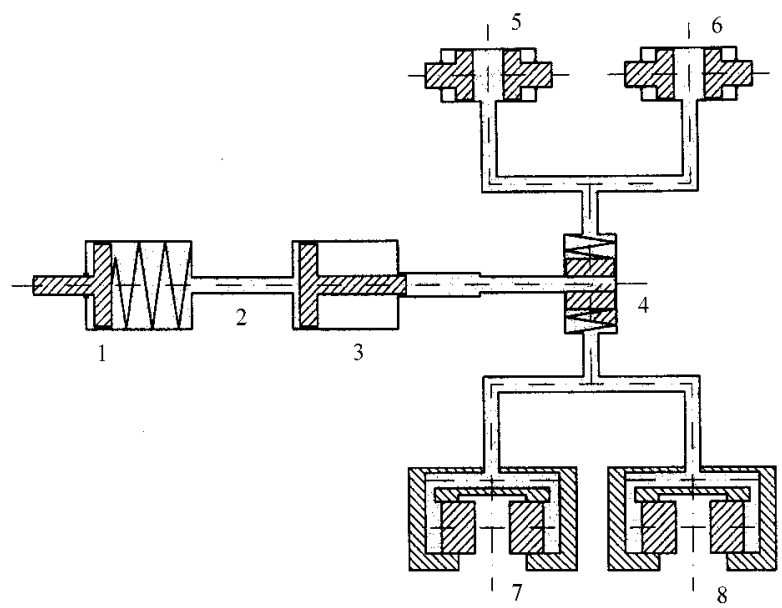

Fig 5. Principle scheme of the hydraulic brake system: 1 - main cylinder, 2 - pipeline, 3 - hydraulic amplifier, 4 - two contours separator; 5, 6 - rear axle brake cylinders; 7,8 - front axle brake cylinders 
The equation of piston number 1 movement can be written $[11,12,25]$ :

$$
\begin{aligned}
& m_{1} \ddot{x}_{1}=\sum F=F_{s p}-k\left(x_{0}+x_{1}\right)- \\
& F_{t r} \operatorname{sign}\left(\dot{x}_{1}\right)-S_{1}\left(p_{1}-p_{a t m}\right) ;
\end{aligned}
$$

where: $m_{1}$ - weight of piston; $\ddot{x}_{1}, \dot{x}_{1}, x_{1}$-acceleration, velocity and position of piston $1 ; F_{s p}$ - pressing force; $k$-stiffness of the spring; $x_{0}$ - initial compression of the spring; $F_{t r}$ - friction force; $S_{1}$ - area of the cylinder cross-section; $p_{1}$ - pressure in 1-st cavity; $p_{\text {atm }}$-atmospheric pressure.

This equation (5) is solved by the Euler method [23], taking into consideration boundary conditions of piston 1 movement. Fluid pressure in the 1-st cavity is solved using equation of debit $[11,12,25]$ :

$$
Q_{1}=S_{1} \dot{x}_{1}-\frac{V_{10}-S_{1} x_{1}}{K} \frac{d p}{d t}-S_{2} v_{21}=0 ;
$$

where: $V_{10}$ - initial volume of 1 -st cavity; $v_{21}$ - fluid velocity in 1-st point of pipeline $2 ; K$ - modulus of elasticity of fluid.

Equation of the fluid continuity can be written in a differential form as follows [11, 12, 25]:

$$
\frac{\partial}{\partial t}(S(x) \rho)+\frac{\partial}{\partial x}(S(x) \rho v)=F_{1}(x) ;
$$

where: $\rho$ - density of fluid; $v$-velocity of fluid; $S(x)$ area of the pipeline cross-section; $F_{1}(x)$ - discharge of fluid mass to the unit of the length in the pipeline. $12,25]$

Equation of fluid flow impulse (momentum) [11,

$$
\begin{aligned}
& \frac{\partial}{\partial t}(S(x) \rho v)+\frac{\partial}{\partial x}\left(S(x)\left(p+\rho v^{2}\right)\right)+ \\
& \Pi(x) \tau+S(x) \rho a_{x}=F_{2}(x)+p \frac{\partial S}{\partial x} ;
\end{aligned}
$$

where: $p$ - fluid pressure; $\Pi(x)$ - perimeter of the pipeline cross-section; $\tau$ - tangential fluid stress in the inner surface of the pipeline; $a_{x}$ - acceleration along $x$ axis; $F_{2}(x)$ - kinetic energy of the fluid flow in the pipeline to the unit of area.

In this paper a motor vehicle hydraulic anti-lock brake system (ABS), consisting of a hydraulic brake system (Fig 6), electromagnetic valve and a wheel brake cylinder, is considered. The main components of the system are shown in Fig 5.

ABS operates by evaluating two main parameters. These are the changes in the wheel angular deceleration and wheel slip. The wheel deceleration is determined by the differentiation of the wheel angular velocity captured by velocity sensor, and the tyre slip ratio is estimated comparing the current wheel angular velocity with the angular velocity calculated from the absolute speed of

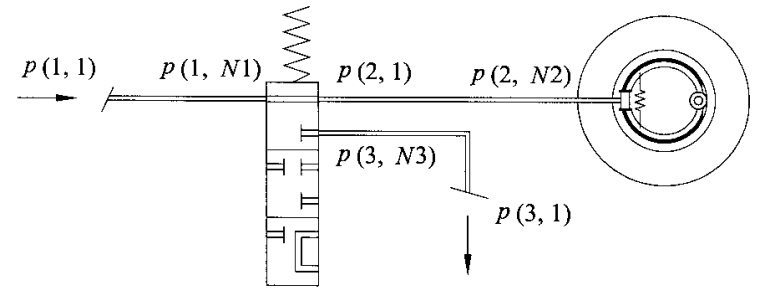

Fig 6. Part of motor vehicle anti-lock brake system

the motor vehicle which is called the reference speed. The equation of tyre slip $\lambda$ can be written as follows [11, 12]:

$$
\lambda=1-\frac{\omega(t) R(t)}{v(t)} ;
$$

where: $\omega$ - angular velocity of motor vehicle wheel; $R$ - radius of wheel; $v$-speed of motor vehicle.

The derivation of tyre slip of wheel $i$ can be written as follows:

$$
\frac{d \lambda_{i}}{d t}=-\frac{1}{v_{i}^{2}}\left(\left(\dot{\omega}_{i} R_{i}(t)+\omega_{i} \dot{R}_{i}(t)\right) v_{i}-\omega_{i} R_{i}(t) \dot{v}_{i}\right) .
$$

In a mathematical model motor vehicle wheel angular velocity and radius, and linear speed and deceleration are determined from the motor vehicle movement equations system. So, combining the motor vehicle movement equations system with the motor vehicle hydraulic anti-lock brake system and the derivation of tyre slip of each wheel, we get a full system of equations of a motor vehicle braking process.

\section{Mathematical Model of the Road Guardrail and Model of Interaction between Motor Vehicle and Road Guardrail}

Road guardrail, for example, parapetic reinforced concrete guardrail (Fig 7), is simulated in a straight line segment with known coordinates $x_{D_{i}}, y_{D_{i}}$ and $z_{D_{i}}$ of nodes [1, 5-9].

When studying the interaction between the motor vehicle with road guardrail, the assumption that the road guardrail does not deform i.e., nodes of road guardrail line segment do not change their position at the moment of impact and after it on the road shall be taken into consideration.

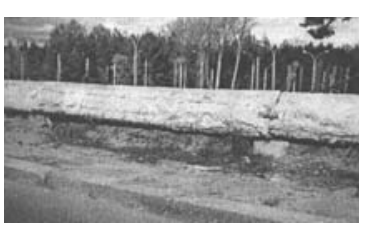

a)

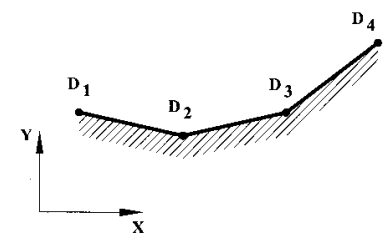

b)
Fig 7. Road guardrail: a - beam reinforced concrete guardrail; $b$ - circuit of guardrail 
The interaction between the motor vehicle and the road guardrail is simulated by a viscous-elastic (KelvinFoight) element $[1,5]$. Such element is added at the point of interaction between the motor vehicle and the road guardrail in the direction of normal to the motor vehicle contour.

Characteristics of the element are described by the following dependence:

$$
F_{n}=k \Delta+h \dot{\Delta}
$$

where: $F_{n}$-interaction force between motor vehicle and road guardrail in the direction of normal to the motor vehicle contour (Fig 8); $k$-element stiffness coefficient; $h$-element mechanical energy damping coefficient; $\Delta-$ deformation; $\dot{\Delta}$-deformation velocity.

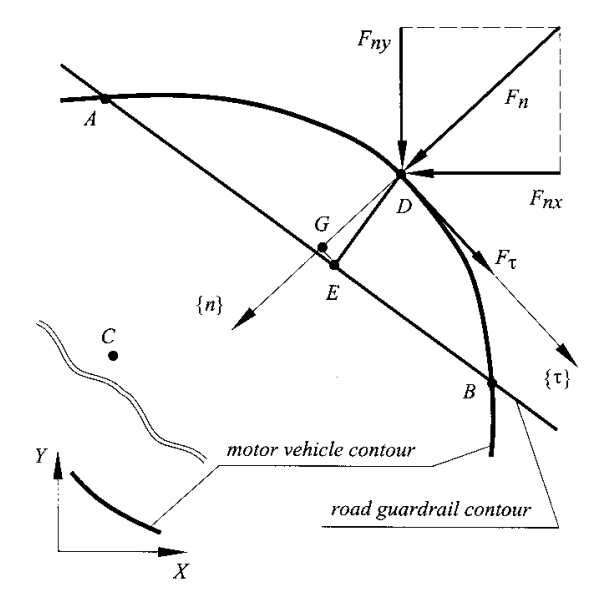

Fig 8. Identification circuit of the interaction forces between the motor vehicle and the road guardrail

\section{Results of a Computer Aided Test}

To solve the presented general dynamic mathematical model (which consists of dynamic model of a motor vehicle with a hydraulic brake system, a model of road pavement surface, a model of road guardrail, a model of the interaction between motor vehicle wheels and road pavement surface and a model of the interaction between a motor vehicle and road guardrail), the following results are obtained during the computer aided test using application packages Compaq Visual Fortran Professional v 6.6 [26] and Waterloo Maple 8.0 [27]:

- motor vehicle movement trajectories, when it is braking at various initial conditions and at various certain pavement surface of the road section under investigation (Fig 9);

- dependences of vertical displacement of a motor vehicle wheel bottom nodal point on the longitudinal coordinate of the road, when a motor vehicle drives on the speed reduction bump ("sleeping policeman") (Fig 10);

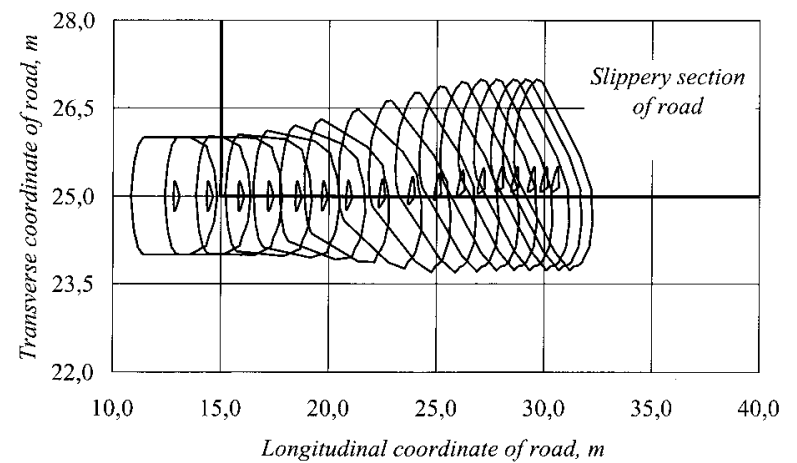

a)

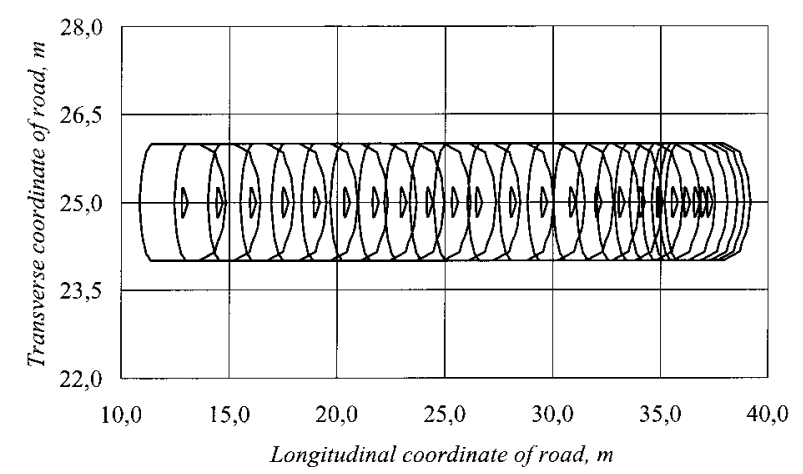

b)

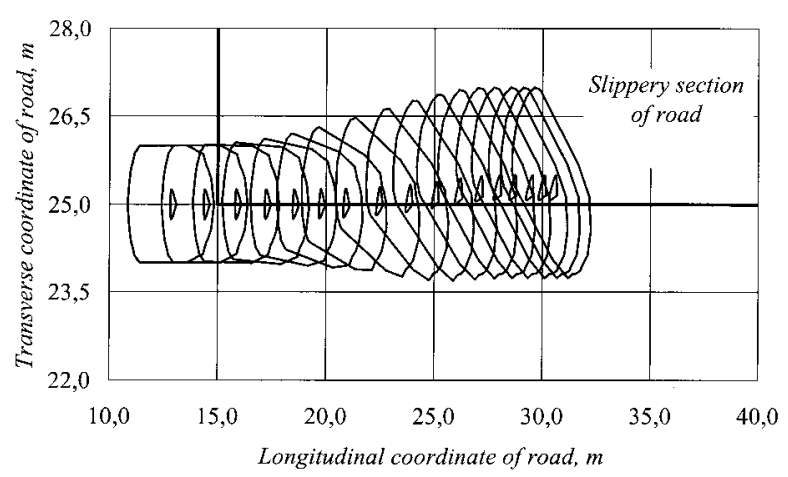

c)

Fig 9. Motor vehicle movement trajectories (view from top), the initial driving speed is $60 \mathrm{~km} / \mathrm{h}$ : a - road pavement is dry asphalt, braking all wheels; $b$ - road pavement is dry asphalt, braking two front or rear wheels; $\mathrm{c}$ - when there is a slippery section on the road, braking all wheels

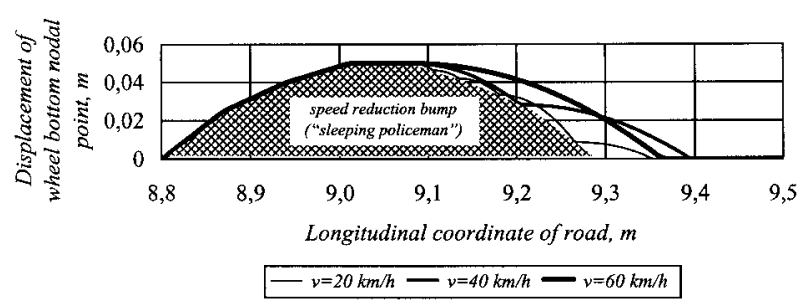

Fig 10. Dependence of the motor vehicle wheel bottom nodal point vertical displacement on the longitudinal coordinate of the road, when the motor vehicle drives on the speed reduction bump ("sleeping policeman") 
- dependences of normal reactions, which influence road pavement surface on the longitudinal coordinate of the road, when a motor vehicle drives on the speed reduction bump ("sleeping policeman") (Fig 11);

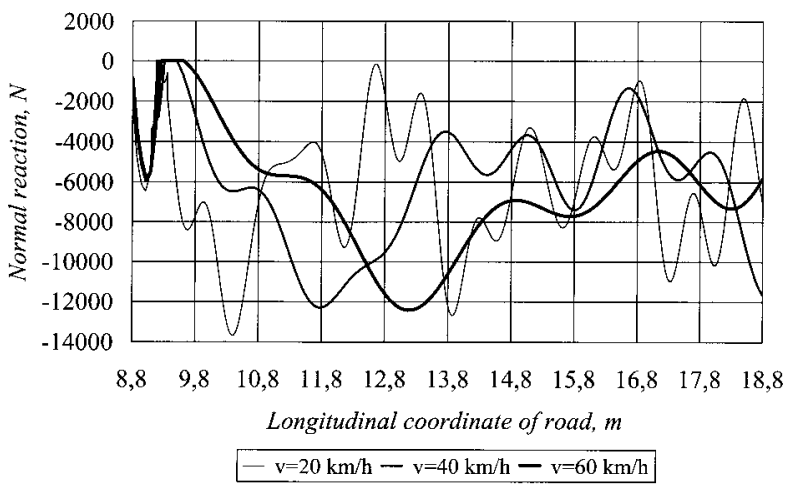

Fig 11. Dependence of the motor vehicle wheel normal reaction, which influences road pavement surface, on the longitudinal coordinate of road, when the motor vehicle drives on the speed reduction bump ("sleeping policeman")

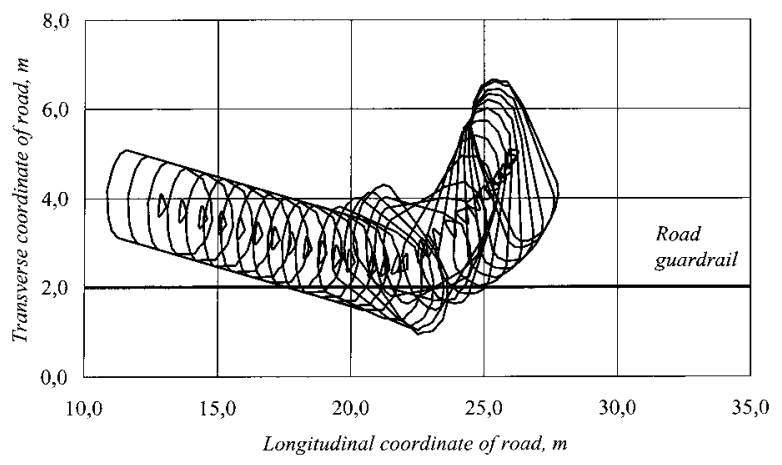

a)

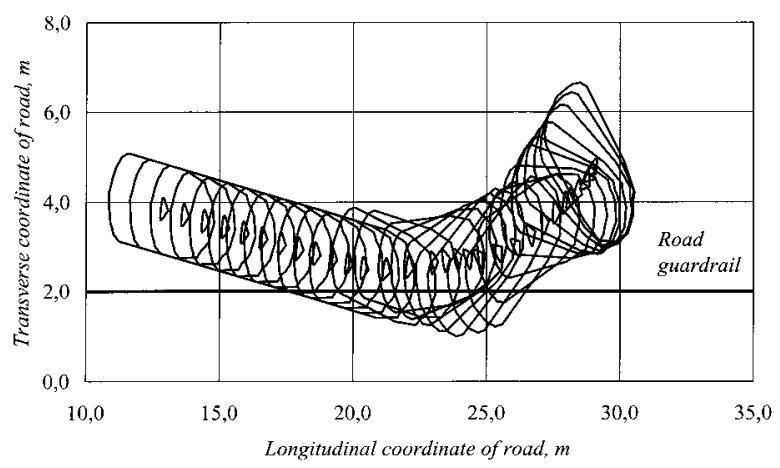

b)

Fig 12. Motor vehicle movement trajectories (view from top) before and after its interaction with parapetic reinforced concrete guardrail, the initial driving speed is $v=60 \mathrm{~km} / \mathrm{h}$ and the initial angle of interaction is $\alpha=10^{\circ}$, road pavement is: $\mathrm{a}$ - dry asphalt; $\mathrm{b}$ - wet asphalt
- motor vehicle movement trajectories before and after its interaction with a parapetic reinforced concrete guardrail (presented in Fig 7) at various certain pavement surface of the road section under investigation (Fig 12);

- dependences illustrating the work of a motor vehicle braking system: dependences of fluid pressure and fluid velocity (Fig 13) on time in typical ABS point $(2,1)$, presented in Fig 6; dependence of motor vehicle wheel braking force (Fig 14);

- results of a motor vehicle braking system simulation (speed of motor vehicle, angular velocity of motor vehicle wheel, tyre slip and tyre friction) at various certain pavement surface of the road section under investigation (Fig 15).

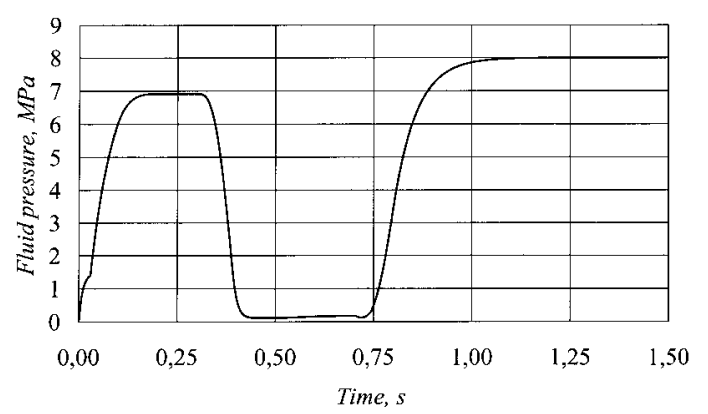

a)

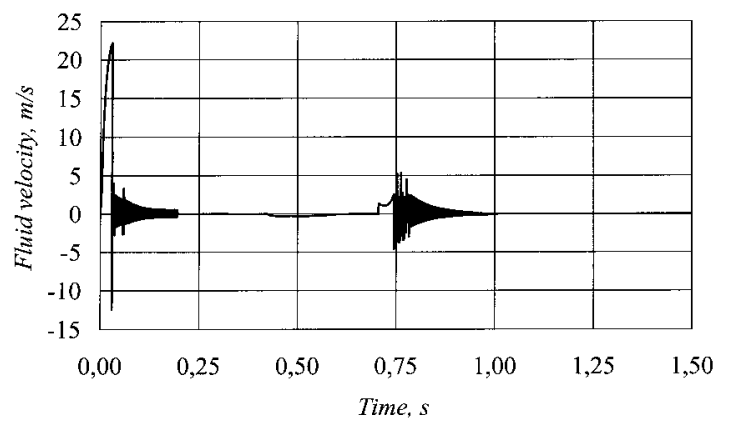

b)

Fig 13. Dependences of fluid pressure and velocity on time in typical ABS point $(2,1)$ presented in Fig 6: $\mathrm{a}$ - fluid pressure; $\mathrm{b}$ - fluid velocity

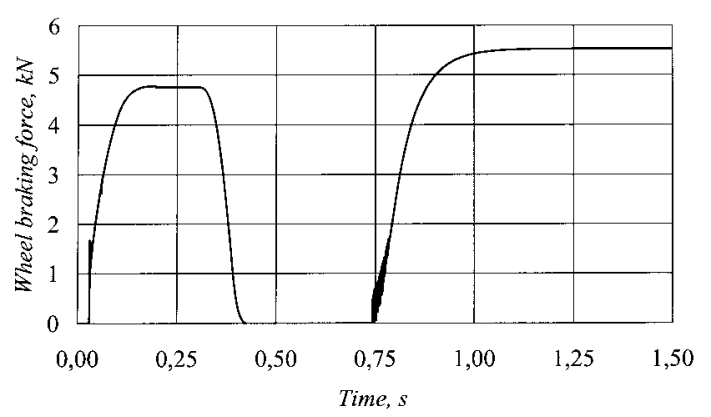

Fig 14. Dependence of motor vehicle wheel braking force 


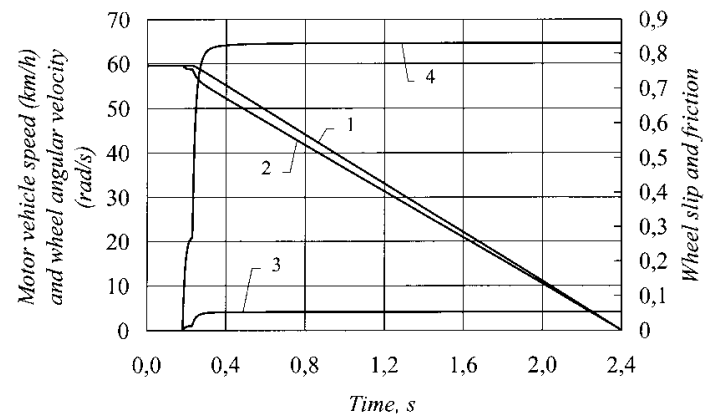

a)

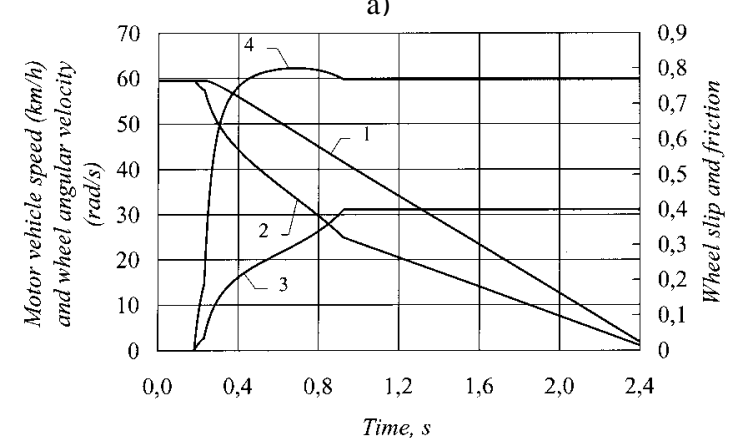

b)

Fig 15. Results of motor vehicle braking system simulation: $\mathrm{a}$ - road pavement is dry asphalt; $\mathrm{b}$ - road pavement is wet asphalt; 1 - speed $v$ of motor vehicle; 2 - angular velocity $\omega$ of motor vehicle wheel; 3 - tyre slip $\lambda ; 4$ - tyre friction $\mu$

\section{Conclusions}

1. A general dynamic mathematical model (which consists of a dynamic model of a motor vehicle with a hydraulic brake system, a model of road pavement surface, a model of road guardrail, a model of the interaction between motor vehicle wheels and road pavement surface and a model of the interaction between a motor vehicle and a road guardrail) is presented.

2. Taking into consideration the presented general mathematical model and computer aided test results it is possible to investigate various road transport traffic situations as well as to investigate various transport traffic safety problems, for example what type and where road guardrail shall be mounted, what curvature ray of the road shall be selected so that the motor vehicle would not drive off the road carriageway, which driver caused an accident etc.

3 . The presented general mathematical model is developed for road accidents experts to investigate accidents on the roads, roads designers to investigate existing road sections and to design road sections, other experts and designers for the identification of motor vehicle characteristics when it interacts with road guardrails, for the identification of motor vehicle braking characteristics, for the investigation of any failure of a hydraulic brake system by changing the boundary conditions (fluid pressure in any point of pipelines, motion of pistons, air quantity etc.).

\section{References}

1. Prentkovskis, O. Interaction between the Vehicle and Obstacles: Summary of Doctoral Dissertation (Technological Sciences, Transport Engineering). Vilnius: Technika, 2000. $56 \mathrm{p}$.

2. Lukoševičienè, $O$. The accidents analysis and simulation. Monograph (Autoịvykiu analizè ir modeliavimas. Monografija). Vilnius: Technika, 2001. 244 p. (in Lithuanian).

3. Prentkovskis, O.; Bogdevičius, M. Dynamic of a Motor Vehicle Talking into Consideration their Interaction of Wheels and Road Pavement Surface. Transport, Vol XVII, No 6, Vilnius: Technika, 2002, p. 244-253.

4. Prentkovskis, O. Definition of the Motor Vehicle Elements Vibrations. Journal of Vibroengineering, 2003, Vol 5, No 1 (10). p. 19-24.

5. Transport: Technologies, Economics, Environment, Health. Monograph (Transportas: technologijos, ekonomika, aplinka, sveikata. Monografija). Vilnius: Technika, 2003. 876 p. (in Lithuanian).

6. Prentkovskis, O.; Bogdevičius, M. Dynamics of the Vehicle Interaction with the Guardrail under Various Road Surface Conditions. In: Proceedings of the 2nd Safety on Road International Conference, 21-23 October 2002, Kingdom of Bahrain: 5 p. (CD electronic form).

7. Bogdevičius, M.; Prentkovskis, O. Simulation of Road Guardrails. Transport Engineering (Transportas), Vol XVI, No 4. Vilnius: Technika, 2001, p. 123-128.

8. Prentkovskis, O.; Bogdevičius, M.; Lingaitis, L. P. Simulation of the System "Road - Obstacle - Vehicle". In: Collection of Scientific Works of Department of Applied Mechanics (Zeszyty naukowe katedry Mechaniki stosowanej), No 17. Gliwice: Politechnika Šląskiej w Gliwicach, 2001, p. 169-176.

9. Bogdevičius, M.; Prentkovskis, O. Requirements for Road Fences and Their Characteristics. Transport Engineering (Transportas), Vol XIII, No 3. Vilnius: Technika, 1998, p. 115-119.

10. Pečeliūnas, R.; Lukoševičienè, O.; Prentkovskis, O. A Mathematical Model of the Vibrating System Equivalent to the Vehicle in the Mode of Emergency Braking. Transport, Vol XVIII, No 3. Vilnius: Technika, 2003, p. 136142.

11. Bogdevičius, M.; Vladimirov, O. Simulation of Automobile Hydraulic Brake System. Mechanics (Mechanika), No 3 (35). Kaunas: Technologija, 2002, p. 67-70.

12. Bogdevičius, M.; Vladimirov, O. Dynamic Processes in the Hydraulic Braking System of Transport Vehicle. In: Proceedings of The Fourth International Conference "Heavy machinery HM 2002”, Kraljevo, 28-30 June, 2002. Kraljevo: Riza, 2002, p. E.37-E.40.

13. Rutka, A.; Sapragonas, J. The Role of a Tire in Vehicle and Road Interaction. Transport, Vol XVII, No 2. Vilnius: Technika, 2002, p. 39-45.

14. Ambrósio, J. An Integrated Finite Element and Multibody Method for Frontal Oblique Vehicle Impact Analysis. In: Proccedings of the European Conference on Computational 
Mechanics "ECCM - 2001", June 26-29, 2001, Cracow, Poland, (CD electronic form).

15. DiMaggio, S. J.; Bieniek, M. P. Vehicle dynamics using a limit surface treatment of the tyre - road interface. In: Proceedings Instn Mech Engrs, Vol 212, Part D, 1998, p. 347356.

16. Williams, T. D.; de Pennington, A.; Barton, D. C. The Frontal Impact Response of a Spaceframe Chassis Sportscar. In: Proceedings Instn Mech Engrs, Vol 214, Part D, 2000, p. $865-873$.

17. Wong, J. Y. Theory of Ground Vehicles. New York: John Willey \& Sons, 1978.

18. Giergiel, J.; Śmieszek, M. Modelling of Automated Guided Vehicle Movement along Curvilinear Trajectory. In: Collection of Scientific Works of Department of Applied Mechanics (Zeszyty naukowe katedry mechaniki stosowanej), No 15. Gliwice: Wydawnictwo Katedry Mechaniki Stosovwanej, 2001, p. 101-106 (in Polish).

19. Henson, S. E.; Huang, M.; Hultman, R. W.; Parekh, I. S.; Grush, E. S.; Pike, J. A. Testing the Side Impact Tests: Method and Some Initial Results. In: Proceedings of Tenth International Technical Conference on Experimental Safety Vehicles. July 1-4, 1985. Oxford, England, p. 667-709.

20. Trella, T. J.; Kanianthra, J. N. Occupant Response Sensitivity Analyses Using a Lumped Mass Model in Simulation Car - to - Car Side Impacts. In: Proceedings of Tenth
International Technical Conference on Experimental Safety Vehicles. July 1-4, 1985. Oxford, England, p. 755-771.

21. Sakurai, M.; Harigae, T.; Ohmae, H.; Nakamura, Y.; Watanable, K. Study on Side Impact Tests Methods. In: Proceedings of Twelfth International Technical Conference on Experimental Safety Vehicles, Vol 2. May 29 - June 1, 1989. Göteborg, Sweden, p. 983-993.

22. Chachaturov, A. A. et al. Dynamics of the System Road Tyre - Automobile - Driver (Динамика системы дорога - шина - автомобиль - водитель). Moscow: Mashinostrojenije, 1975. 535 p. (in Russian).

23. Korn, G.; Korn, T. Reference Book on Mathematics for Scientific Workers and Engineers (Справочник по математике для научных работников и инженеров). Moscow: Nauka, 1968. 720 p. (in Russian).

24. Crisfield, M. A. Non-linear Finite Element Analysis of Solid and Structures, Vol 1 - 2. John Wiley \& Sons, 1997.

25. Bogdevičius, M. Simulation of Dynamic Processes in Hydraulic, Pneumatic and Mechanical Drivers and Their Elements: Summary of the Research Report Presented for Habilitation. Vilnius: Technika, 2000. 96 p.

26. Schick, W.; Silverman, G. Fortran 90 and Engineering Computation. John Wiley \& Sons, 1995, 425 p.

27. Aladjev, V.; Bogdevicius, M.; Prentkovskis O. New Software for Mathematical package Maple of releases 6, 7 and 8. Monogpaph. Vilnius: Technika, 2002. 404 p. 